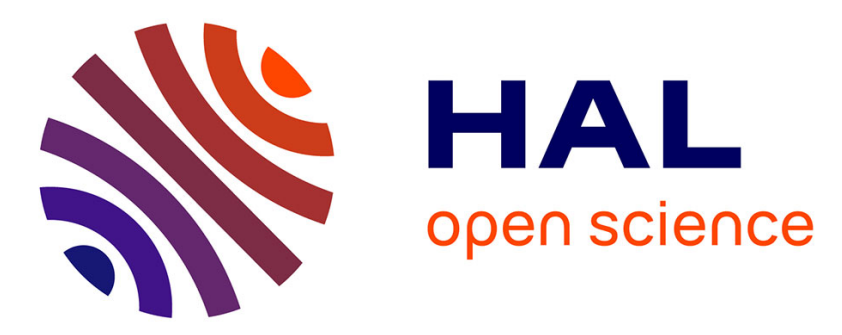

\title{
A standard-based business repository for on-demand manufacturing execution system $\mathrm{s}$ Ikbal Mansour, Pierre-Alain Millet, Valerie Botta-Genoulaz
}

\section{To cite this version:}

Ikbal Mansour, Pierre-Alain Millet, Valerie Botta-Genoulaz. A standard-based business repository for on-demand manufacturing execution system s. Production Planning and Control, 2018, 29 (7), pp.602-613. 10.1080/09537287.2018.1456691 . hal-01762483

\section{HAL Id: hal-01762483 \\ https://hal.science/hal-01762483}

Submitted on 25 Apr 2018

HAL is a multi-disciplinary open access archive for the deposit and dissemination of scientific research documents, whether they are published or not. The documents may come from teaching and research institutions in France or abroad, or from public or private research centers.
L'archive ouverte pluridisciplinaire HAL, est destinée au dépôt et à la diffusion de documents scientifiques de niveau recherche, publiés ou non, émanant des établissements d'enseignement et de recherche français ou étrangers, des laboratoires publics ou privés. 


\title{
A Standard-Based Business Repository for On-Demand Manufacturing Execu- tion Systems
}

\author{
Production Planning \& Control Journal
}

Ikbal Mansour ${ }^{2}$, Pierre-Alain Millet $\left.{ }^{1}{ }^{*}\right)$, Valérie Botta-Genoulaz ${ }^{1}$

1.Univ Lyon, INSA-Lyon, DISP EA4570, F-69621, France

2.Univ Lyon, INSA-Lyon, CNRS, LIRIS UMR5205, F-69621, France

\{ikbal.mansour, pierre-alain.millet,valerie.botta\}@insa-lyon.fr

(*) corresponding author: INSA-Lyon, DISP, Bâtiment Léonard De Vinci, 21 avenue Jean Capelle, 69621 Villeurbanne cedex, France, +33607503381

\section{Highlights}

- An expert-based approach to semantic alignment in MES projects

- A Standard-Based Repository for Manufacturing Execution Systems

- A MES meta-model to align heterogeneous repositories

- Enrichment of ISO 62624 models using the SCOR model

- An industrial platform as a proof of concept

\section{Abstract}

In manufacturing execution system (MES) projects, knowledge is heterogeneous and is applied partially in each software package. Consistency is therefore critical. Some standard business reference models exist, such as the ISO62264 standard for manufacturing execution systems (known as ISA S95), or the SCOR reference model for supply chain planning (SCP) and execution (SCE). These reference models have some overlaps. For example, traceability is part of both MES and SCE packages. A consortium of manufacturing software publishers for industry has launched an "MES on demand" platform using services from different packages. This paper presents the enriched business repository model built to facilitate business heterogeneity. It is used to align different business repositories ( $\mathrm{B}-\mathrm{B}$ alignment) and different business and software packages (B$\mathrm{S}$ alignment). It likewise serves to align customer requirements with the repository (B$\mathrm{C}$ alignment). The consortium is then "S95 compliant" when knowledge supported by the different actors is included.

Keywords: Enterprise integration, Interoperability, Manufacturing Execution System, SCOR, Repository Alignment

\section{Acknowledgment}

We thank the Rhône-Alpes Regional Council (France) and ERDF (European Regional Development Fund) for its financial support for the "MES project" as part of the EDIT cluster. We also thank all "MES project" members and software publishers for their business expertise, and the LISTIC laboratory, which worked on the functional layer and the web services orchestration. 


\section{Introduction}

A consortium of manufacturing software editors launched an industrial initiative to build a MES platform, using services from various packages, including Manufacturing Execution Systems (MES) and Supply Chain Execution (SCE). This type of platform is called a "MES on demand", in the sense of the "ERP on demand" described in (Koslowski and Strüker 2011).The consortium members' aim was to facilitate the pooling of their capabilities so that they could answer calls for proposals more efficiently, in a MES market characterized by big players with large integrated solutions. To enable such an "on-demand" MES to manage the heterogeneity of the various trades, software packages and business reference models involved in a project, it is necessary to formalize the knowledge of business processes and business objects that will be supported by applications and their interactions. This knowledge is implemented in different ways and often partially in each software package. This heterogeneity enables us to identify three scientific issues related to: 1) semantically aligning business repositories (Figure 1, B-B, Business to Business repositories); 2) formalizing companies' needs with the repository (Figure 1, B-C, Business repository and Client requirements); and 3) aligning the business repository with functional layer components (Figure 1, B-S, Business to Software). These three alignment issues are involved in the capacity to build an "on demand" multi-publisher MES solution as:

1) several software packages are usually involved and are heterogeneous;

2) client requirements are expressed in the client's business language and have to be mapped onto the repository language;

3) the capability to link a standard business repository and a standard web service of applications is a condition for mastering the implementation of a client business model in an orchestration of existing web services.

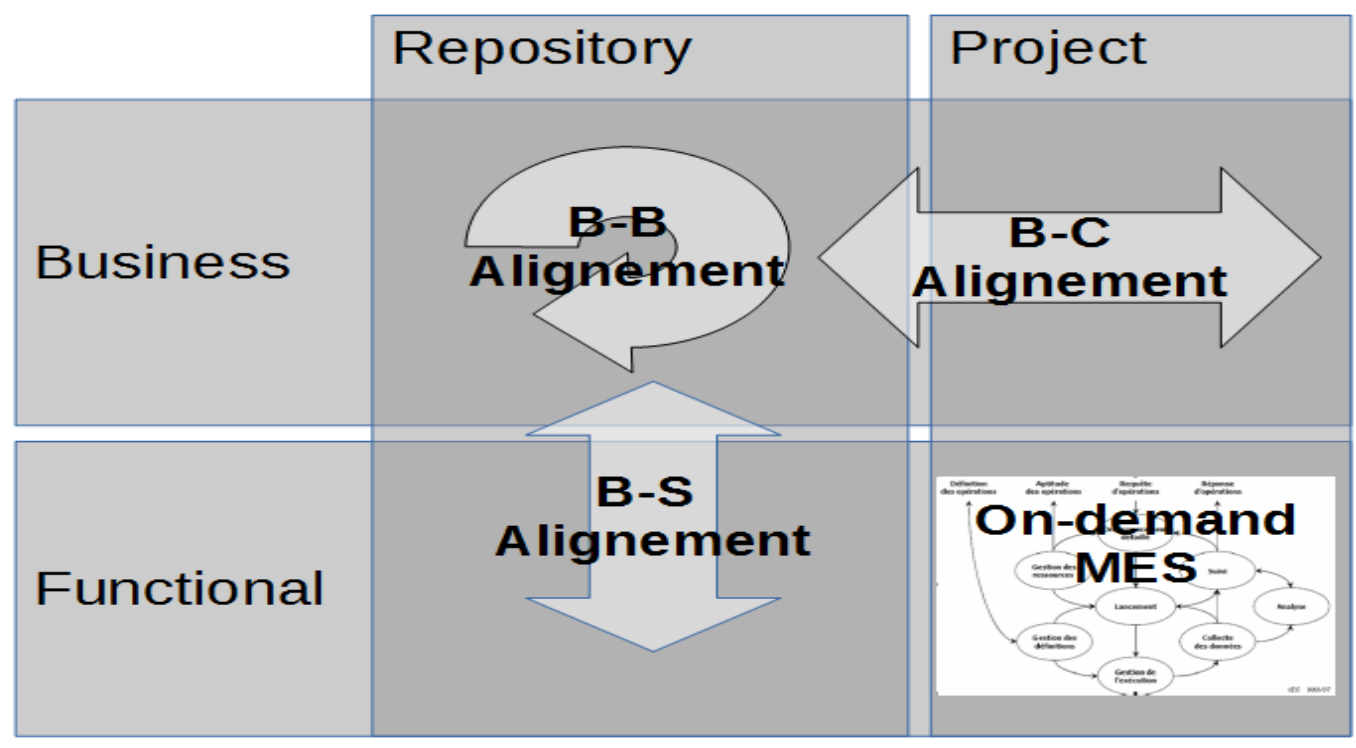


Possible place for Figure 1. Three issues of alignment involving the business layer

Due to the MES diversity encountered in business cases, client requirements are generally met with multiple software packages. This requires consistency and interoperability to be built as the capabilities of software solutions are matched with a company's processes. In such an "on demand MES", we have to ensure consistency of the different interpretations of business processes and objects. This is the aim of the proposed MES business repository.

Scientists use the IEC/ISO 622642003 Enterprise-Control System Integration standard to define and sustain the structure of a MES business repository (IEC/ISO 62264 2003). To meet common requirements in manufacturing and logistics, we enhance this ISO/IEC-oriented MES business repository with some constructs of the Supply Chain Operations Reference (SCOR) model from the Supply Chain Council (SCC 2009). This enhancement illustrates the horizontal alignment between business repositories (Figure1, B-B). The proposed repository provides support for consistency, both in modelling and orchestrating processes, and in implementing solutions and training. In order to align the business repository with functional layer components and to make this repository "usable" in a SOA (Service Oriented Architecture) approach (Marks and Bell 2006), we then align the business processes and business objects with web service operations and parameters proposed by MES applications (vertical alignment, Figure1, B-S). Independently of its implementation in each application, the MES business repository thus obtained will provide a base for a semantic definition of manufacturing companies' requirements. These requirements, that are a set of business processes and objects, are then specified, based on standard business models. This illustrates the horizontal alignment between the MES business repository and the identified requirements in a context of manufacturing companies' engineering projects (Figure 1, B-C).

This paper presents a standard-based business repository built to help the design of an "ondemand" MES solution in a model-driven approach. The repository is based on two existing business knowledge repositories (the international norm IEC/ISO 62264, and the business reference model SCOR) completed by business expertise. The enrichment methodology has been presented in another paper.

After a literature review in Section 2, Section 3 briefly presents the framework used, based on ISO 19439 (ISO TC 184 WG1 and CEN TC 310 WG1, ISO 19439 2006). In Section 4 we present the business repository structure, aligned with software packages' capabilities (B-S), built by enrichment of the IEC 62264 standard using the well-known supply chain reference model (SCOR) and some business expertise (B-B), and used to define client requirements (B-C). Section 5 presents the mapping of the enriched MES repository on the Web services of applications involved in the MESTRIA industrial platform. Finally, we conclude, presenting the approach used experimentally for semantic alignment between heterogeneous business repositories.

\section{State of the art}

Information exchange between enterprises' software applications is never only a technical issue requiring different levels of technical protocols. Interoperability has to be addressed at the business and functional levels as well, where issues involving actors and their understanding, cultures, practices, trust etc. arise (Chen and Doumeingts 2003). Misunderstandings and problems of inconsistency occur, with a risk of loss of semantics during the exchange between heterogeneous 
systems. This problem of managing heterogeneous information from different enterprises' systems/applications to achieve a single comprehensive understanding is one of the problems of interoperability. For example, the interpretation of a production order, a schedule, a package or a piece identification number often differs in Enterprise Resource Planning (ERP), MES or Supply Chain Management (SCM) packages. Meaningful and effective interoperability between enterprises requires interoperability at all levels of the firm. Interoperability at the semantic level remains the major challenge for the interoperability of systems (Vernadat 2010; Panetto and Molina 2008). Along with enterprise modelling and architectures, semantic interoperability is therefore one of the other essential pillars supporting enterprise integration and interoperability. In this challenge, the role of business standards or reference models is critical because they contain semantic definitions of business objects. Companies have to map this knowledge with their relevant specific models. To help them use a standard, Zdravkovic (2012) proposes an ontological framework for semantic interoperability using the SCOR reference model. Sakka et al. (2011) compare different representations of semantic content of business models.

Semantic conflicts may arise during the exchange between two systems / software applications. These conflicts may relate not only to data (Ram 2004) but also to the business logic as it is applied (Bussler 2003). Semantic alignment is then a condition of interoperability. It requires one to evaluate the lack of interoperation through the measurement of the semantic gap occurring between the heterogeneous conceptual models (Yahia, Aubry, and Panetto 2012); its automation is difficult and can only be very partial. The alignment process cannot be fully automated. In fact, the alignment of concepts is a task that requires understanding of the semantics (meaning) of these concepts (Ding 2002). Thus, the alignment process requires the knowledge and decisions of the domain's expert. Existing alignment and mapping tools, such as those for ontologies, can only suggest alignment or mapping. However, this alignment remains a human task involving experts with a sound understanding of the business project.

To model the knowledge on business processes, the ISO 19439 standard framework (ISO/TC and CEN/TC ISO 19439 2006) formalizes three dimensions in engineering: the modelling phases in the life cycle of a project; the level of genericity, from the generic to the specific; and the views that allow to read separately different aspects of the model. In view of the industrial context of the research, we simplify this framework by excluding the partial level of genericity, to focus on the repository and project levels. We also exclude organization and resources, to focus rather on information and functions, which are the core with which we align software applications and client requirements in the on-demand MES. We then implement this approach using the ARIS platform and language (Scheer 2005), which is compliant with the 19439 framework (Chen et al. 2008). The ARIS platform was used as a design platform to build the repository alignment. The resulting repository can then be transferred using XML export/import to any industrial platform.

This issue of interoperability and heterogeneity is crucial for MES when manufacturing resources, processes, and control methods are heterogeneous. MESA (Manufacturing Enterprise Solutions Association) proposes a formal definition of MES (MESA 1997b): MES deliver information that enables the optimization of production activities from order launch to finished goods. Using current and accurate data, a MES guides, initiates, responds to and reports on plant activities as they occur. The resulting rapid response to changing conditions, coupled with a focus on reducing non-valueadded activities, drives effective plant operations and processes. The MES improves the return on operational assets as well as on-time delivery, inventory turns, gross margin and cash-flow performance. A MES provides mission-critical information about production activities across the enterprise and supply chain via bidirectional communication. A MES is therefore one of the software solutions 
used to bridge production planning and equipment control systems. To meet the needs of a variety of manufacturing environments, MESA identified 11 principal MES functions. Some of these are directly linked to the process, such as scheduling and quality control, while others, such as resource management and traceability, are best described as cross-functional (MESA 1997a). The manufacturing systems of the future (Almada-Lobo, 2015) strengthen the role of MES supporting the paradigm of smart, distributed manufacturing, with growing requirements for integration in a more heterogeneous context.

The academic research on integration problems points out the importance of the integration of MES with other information systems. Guangke et al. (2009) propose a service-oriented MES framework to allow easy reconfiguration of MES required by changing business environments. Saenz de Ugarte et al. (2009) present a literature review of MES systems, showing several considerations on commercial MES solutions, and major issues related to their use and implementation. The interoperability between MES and Supply Chain Execution systems (SCE) is highlighted for performance measurement in e-manufacturing (Teran \& al, 2014). These authors report on in-depth discussions on the research areas $t \quad$ hat would have to be explored in order to resolve the increased complexity of MES systems.

A well-known business standard for MES is the ISA-95 standard published by the Instrumentation, Systems \& Automation (ISA) Committee. It includes a functional enterprise-control model (Part 1, Figure 5) and object models (Part 1, Chapter 7). An academic version has been published as IEC/ISO 62264 (IEC/ISO 62264. 2003). This standard deals with the formalization of exchange, around the manufacturing system, with other areas of the company. Its function model puts the manufacturing control function in a central position. The MES is then an intermediary between the various departments of the company. ISA-95 is widely adopted by market players for the design of information flows between shop floor applications and those at a higher level. It also allows the industry to have a consistent terminology, used for example to build a reference activity model for smart factory (Kiwook \& al, 2016).

The IEC/ISO 62264 is implemented in an XML schema known as "B2MML" (Business To Manufacturing Markup Language). This is a living standard. The Version 5 of B2MML, used for this article, has generalized the concept of "operations" which can be production, maintenance, quality control, and others, and which were modelled separately in previous versions. These changes have led to a new version of IOS/IEC 62264 in 2013.

MESs are used, inter alia, by the aerospace, automotive, semiconductor, optoelectronic, pharmaceutical and petrochemical industries (Vinhasis 1998, Larson 1997, Hakanson 1996, Adler et al. 1995), not only for production but also for maintenance (Levrat 2008). For example, a MES can meet stringent quality and manufacturing standards set by the U.S. Food and Drug Administration (FDA), and it can help reduce overall costs (Vinhais 2004).

Both MESA and ISA highlight the diversity of software capabilities required for MES, with software packages covering different manufacturing domains that often overlap. Other reference models for related enterprise activities have shared coverage with the IEC/ISO 62264 model, for example the SCOR reference model (Jung 2017). The problem of semantic alignment is then a major challenge for MES projects. The concept of "on-demand" MES can be a flexible approach to help the three alignments presented in Section 1. 


\section{The MES Business Repository for business alignment}

\subsection{The Alignment Framework and the Proposed Meta-Model}

We use a simplified framework based on the enterprise architecture proposed in the ISO 19439 standard. This allows us to model the IEC/ISO 62264 constructs and to manage the main issue of relationships between the specific view of a manufacturing company and the standard view of business knowledge. The manufacturing company is a client using the framework to model its own business processes. We consider two phases of ISO 19439: the requirement definition phase implemented in a "business layer" of our meta-model, used to describe the repository and client needs independently of their software implementation, and the design specification phase implemented in the functional layer of our meta-model, used to describe the software capabilities and client configuration. In this framework, the repository level is considered both as the 'generic' and 'partial' levels of the ISO 19439 standard, while the project level used to model client requirements and systems is the implementation of the 'particular' level of the standard.

Likewise, we use only the informational and functional views of the standard, excluding the organizational and resource views, because the IEC/ISO 62264 standard defines only data and function models. An extension to these views will be dealt with in future work, but we consider that the results built on these first two views are a first step towards such an extension.

To be able to establish an alignment between the different knowledge of companies, software editors and standards, it is necessary to share a common representation of the different constructs used to model such knowledge. We define a meta-model consistent with the proposed modelling framework. The role of this meta-model is to provide rigorous model building (Bigand et al. 2004), and thus to ensure a coherent reading of the various models, business processes and business objects of the business repository, by all project participants. Regarding the lifecycle phase dimension of the ISO 19439 standard, we focus on the "concept definition" and "requirement" phases. The business and functional models in the genericity dimension at the repository level are then considered in the "concept definition" phase, whereas at project level they are considered in the "requirement" phase. This ensures the conformity of models created in this framework with the generic level, and then for the 
manufacturing companies, with IEC/ISO 62264.

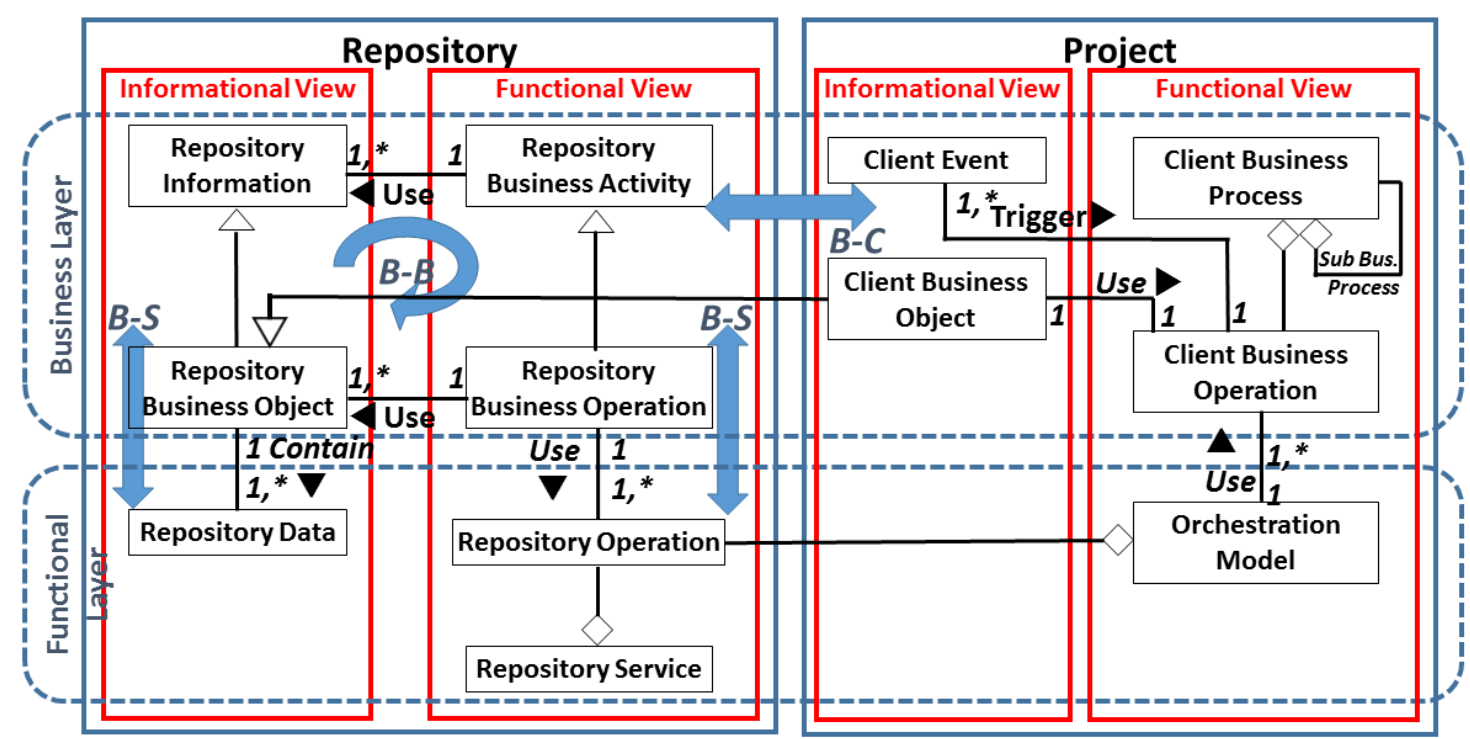

Possible place for Figure 2. Alignment MES meta-model

The meta-model in Figure 2 presents the different constructs used in the simplified framework to show which is used in the different alignments. The left part of the business layer presents the metamodel of the repository, with a first level ensuring compliance with IEC/ISO 62264, and a second level serving to enrich the repository using others business reference models. The functional layer below illustrates the software capabilities (data and services). On the right side, called "project", the business layer shows the meta-model to express clients' business requirements, while the layer beneath it shows its intended application in software services. In this specialized level of the functional layer, the information view is not detailed. In this work, we consider that the implementation of the client business object in the data flow is facilitated with the alignment at repository level between the repository business object and the repository data, but may have to be implemented in the orchestration model, depending of software editors. An answer to this complementary issue is proposed by Verjus (2011).

In this meta-model we represent the B-B alignment at the Repository level of the Business Layer. Between the Repository and Project levels, we represent the B-C alignment. At the Repository level, between the Business and Functional Layers, we represent the B-S alignment.

We hereafter briefly introduce each construct.

Some constructs are based on the IEC/ISO 62264 to represent information and functional views at the two levels of granularity used in this standard.

- Repository Information: Information from IEC/ISO 62264, contained in object models of the standard (common objects such as persons, equipment, assets, and materials; and domain-dependent objects such as schedules, capabilities, etc.). It is used by a Repository Business Activity and is specialized in a Repository Business Object. This Repository Information consists of abstractions of business objects, designed to be compliant with the IEC/ISO 62264 standard. 
- $\quad$ Repository Business Objects: Specialized Repository Information to support a more detailed definition of information flow used in a model (order, warehouse, customer, component, raw material, etc.). It can be tracked by users at an operational level.

- $\quad$ Repository Business Activity: An activity consisting of some business tasks for a certain purpose, and exchanging information (Repository Information). The standard defines eight activities (product, resource, schedule, dispatch, execute, track, collect, analyse) for each of the four domains (production, maintenance, quality and inventory). These are abstractions of actual business activities, which allow a business to be compliant with IEC/ISO 62264.

- Repository Business Operation: A specialization of a Business Activity, which describes some business process steps at an operational level (release a production order, print shipment documents, check tool requirements, etc.).

Some constructs are required to express the client requirements from an informational and functional point of view. A Client Business Process is an "event-based workflow" and requires a construct to identify the events.

- $\quad$ Client Event: A change of the system status triggered by and/or triggering a Client Business Operation. A Client Event is part of the informational view and is used in the functional view.

- Client Business Object: A specialization of the Repository Business Object used in the client project to describe more precisely some aspects of the client informational view of the project.

- $\quad$ Client Business Operation: A specialization of the Repository Business Operation used in the client project to describe more precisely some aspects of the client functional view of the project. Even in very specific situations, we consider that new operations have to be classified as specialization of the repository to ensure the conformity of the final client model with IEC/ISO 62264IEC/ISO 62264.

- $\quad$ Client Business Process: An organized sequence of Client Business Operations triggered and triggering some events. They represent the manufacturing company requirements (schedule process, preventive supplier reminder, etc.). A business process can be detailed using sub-processes and can exchange some information using business objects.

These constructs define the business level of our framework. Considering heterogeneity between repositories of software editors, we do not propose a global meta-model including the functional and technical levels. For on-demand solutions we have to build a loose coupling between all levels. A business definition of a project can be implemented using different functional approaches and different software applications. We therefore define only the relations, which help to implement a business model at the functional level.

- $\quad$ Repository Data: At a functional level, business objects are represented as a structure of data. These data are inputs and outputs of functional operations. They are related to a Repository Business Object.

- Repository Operation: A functional service is composed of web service operations, which are grouped together in a Repository Service for functional reasons, typically when they use the same business object (create, maintain, release, change the same business order). It is used by a Repository Business Operation as an implementation of this operation at functional level.

- Orchestration model: Composed of Repository Operations, and implements the dynamic of some client business operations. 
This meta-model focuses on what is required to build consistency in a standard-based, on-demand MES project. The "use" relation between the business and functional layers is the key to build this consistency. For example, at the business layer, "manufacturing order" for discrete manufacturing and "schedule" for batch manufacturing are differentiated from one another. These business objects can be implemented differently in software solutions. However, while a schedule is sometimes implemented in some software using a list of manufacturing orders per period, where each manufacturing order is defined by a fixed quantity for the period, it can also be implemented in a dedicated object based on capacity and period, so that the cumulative quantity produced across periods can be managed directly.

This meta-model is the framework to build our repository and manage heterogeneous business reference models and heterogeneous software solutions consistently. It is also the framework used to model a customer business case, using, as far as possible, standard repository business operations and objects, and where necessary using variants by defining client business operations, but with the ability to define freely the client business process compliant with the repository. The business consistency of the result is a realistic constraint in the context of an industrial project with a client validation.

\subsection{MES Business Repository}

The proposed MES business repository aims to help experts in the semantic issue of business interoperability, and to help manufacturing companies, whatever their size, to integrate MES software applications and information systems, and to configure their own MES solution by choosing the features that meet their needs. It has to support both the modelling of the company requirements in conformity with the IEC/ISO 62264 standard, and the implementation of services using heterogeneous applications. Our meta-model allows us to ensure conformity with IEC/ISO 62264. All constructs used in a company project are specialized business repository constructs, which are all specializations of IEC/ISO 62264 constructs. The "Business Activities" constructs contain the eight generic activities of the IEC/ISO 62264 standard (business layer in Figure 2).

\subsection{Three alignments to build the repository}

\section{Alignment between business repository and software applications (B-S Alignment)}

When building the MES repository during a MES project for a manufacturing company, the first enrichment is provided by taking into account the business knowledge of the different partners involved, so that the manufacturing client's requirements can be met. Each of them has a certain functional representation of their software capabilities, and different representations of their client's business requirements. A repository of existing web services published by the different software editors has to be defined at the functional level. Using some company business cases to abstract the services described at the business level, we built a list of business operations mapped to the IEC/ISO 62264 constructs. The result is an enrichment of the MES business repository with the knowledge proposed by the different software editors. From the informational point of view, it required some relations between "Repository Data" and "Repository Business Object" constructs, and from the functional point of view, some relations between "Repository Operation" and "Repository Business Operation" constructs. We mapped the web service operations and the inputs/outputs defined by 
software editors with our MES repository. These 161 operations and 1962 data were selected by MESTRIA editors to cover the main software functionalities used in their MES projects.

\section{Alignment between heterogeneous repositories (B-B Alignment)}

The MES repository also had to be enriched with all business expertise involved in a manufacturing project, including other business reference models. As an experiment, we aligned the manufacturing part of the SCOR reference model with the alignment between heterogeneous repositories. This was an issue emerging from business actors, where some of them were involved in logistics activities linked to MES functions, and had differing points of view on "shared content" in a project. This is currently an important business issue in projects where actors from different business domains have to agree on modelling decisions. For example, traceability is a major issue not only for logistics but also for production, quality systems, etc., and it is present both in MES and in SCE applications. Due to the trend towards increasingly integrated systems, the dependencies between SCE and MES lead to numerous semantic alignment issues. Logistics repositories such as SCOR are then used in the context of a MES repository.

The IEC/ISO 62264 and SCOR business scope and granularity levels were compared in order to study the MAKE process, excluding metrics and best practices. We integrated all SCOR elements involved in this MAKE process, 287 SCOR inputs/outputs as Repository Business Objects and 29 SCOR process elements as Repository Business Operations. This allowed us to model all manufacturing processes defined in SCOR, using our repository.

These constructs are generic, and can therefore represent all kinds of businesses. To fit real project requirements, we extended the repository with various business-oriented constructs, taking into account different business typologies and expertise. We used business cases of real projects (Annex D) to enrich the repository.

The result was the MES business used as a glossary to build company business processes employing variants of repository objects to allow for an easy mapping on existing web service operations. We designed the repository on the ARIS modelling platform which is compliant with the 19439 framework and able to develop rules and scripts to evaluate and check consistency of the alignments.

Table 1 shows the ARIS objects used to model meta-model constructs.

- A "cluster" is an informational ARIS object type, which represents a business object independently of its technical implementation in a database. It is the logical view of multiple entity types and relationship types of a data model that are required for describing a complex object.

- An "event" is an informational ARIS object type, which implements the change of status of a business object. An event describes the fact that an information object has taken on a business management-relevant state that controls or influences the progression of the business process. Events trigger functions and are the results of functions. 
- A "function" is a functional ARIS object type, which implements a technical task or activity performed for an object to support one or more business objectives.

Possible place for Table 1. The ARIS objects used

\begin{tabular}{|c|c|c|c|}
\hline $\begin{array}{l}\text { ARIS object } \\
\text { type }\end{array}$ & ARIS graphic & ARIS Construct Definition & MES meta-model constructs \\
\hline Cluster & & $\begin{array}{l}\text { Logical view of a multitude of } \\
\text { entity relationship types of a } \\
\text { data model, which is required } \\
\text { to describe a complex object }\end{array}$ & $\begin{array}{l}\text { Repository Information } \\
\text { Repository Business Object } \\
\text { Client Business Object }\end{array}$ \\
\hline Event & & $\begin{array}{l}\text { A change of the state of an ob- } \\
\text { ject that influences the busi- } \\
\text { ness object }\end{array}$ & Client Event \\
\hline Function & & $\begin{array}{l}\text { A technical task or action per- } \\
\text { formed for an object to support } \\
\text { one or more business objec- } \\
\text { tives }\end{array}$ & $\begin{array}{l}\text { Repository Business Activities } \\
\text { Repository Business Service } \\
\text { Client Business Process } \\
\text { Client Business Operation }\end{array}$ \\
\hline
\end{tabular}

These ARIS object types are used in two types of ARIS model: the "ARIS IE data" model type to describe relations between clusters in the informational view, and the "ARIS Function Allocation Diagram", to describe all relations around some functions. These static models contain the glossary to define business processes using the ARIS Event Process Chain Model.

The "Repository Information" constructs contain the nine common object models, and the Business Activity construct contains the eight activities of the IEC/ISO 62264 standard (Table 2). They are enriched at the functional level and then aligned with data and services proposed by software applications.

Possible place for Table 2. MES repository contents after enrichment

\begin{tabular}{|l|l|l|l|}
\hline Repository Level & Informational View & Repository Level & Functional View \\
\hline $\begin{array}{l}\text { Repository Infor- } \\
\text { mation }\end{array}$ & IEC/ISO 62264: 9 objects & Business Activity & $\begin{array}{l}\text { IEC/ISO 62264: 8 activi- } \\
\text { ties }\end{array}$ \\
\hline $\begin{array}{l}\text { Repository Business } \\
\text { Object }\end{array}$ & $\begin{array}{l}\text { SCOR: } 287 \text { I/O } \\
\text { Experts: } 84 \text { business objects }\end{array}$ & Business Operation & $\begin{array}{l}\text { SCOR: } 29 \text { functions } \\
\text { Experts: } 91 \text { functions }\end{array}$ \\
\hline
\end{tabular}




\begin{tabular}{|l|l|l|l|}
\hline Repository Data & Orchestration: 1962 data & Orchestration model & Editors: 161 Services \\
\hline
\end{tabular}

An example of the alignment of SCOR operations with IEC/IOS 62264 activities is illustrated in Figure 3. Alignment is represented in a model using different relationships, a composition relation named in ARIS "is a sub-state", or a general relation named "corresponds to".

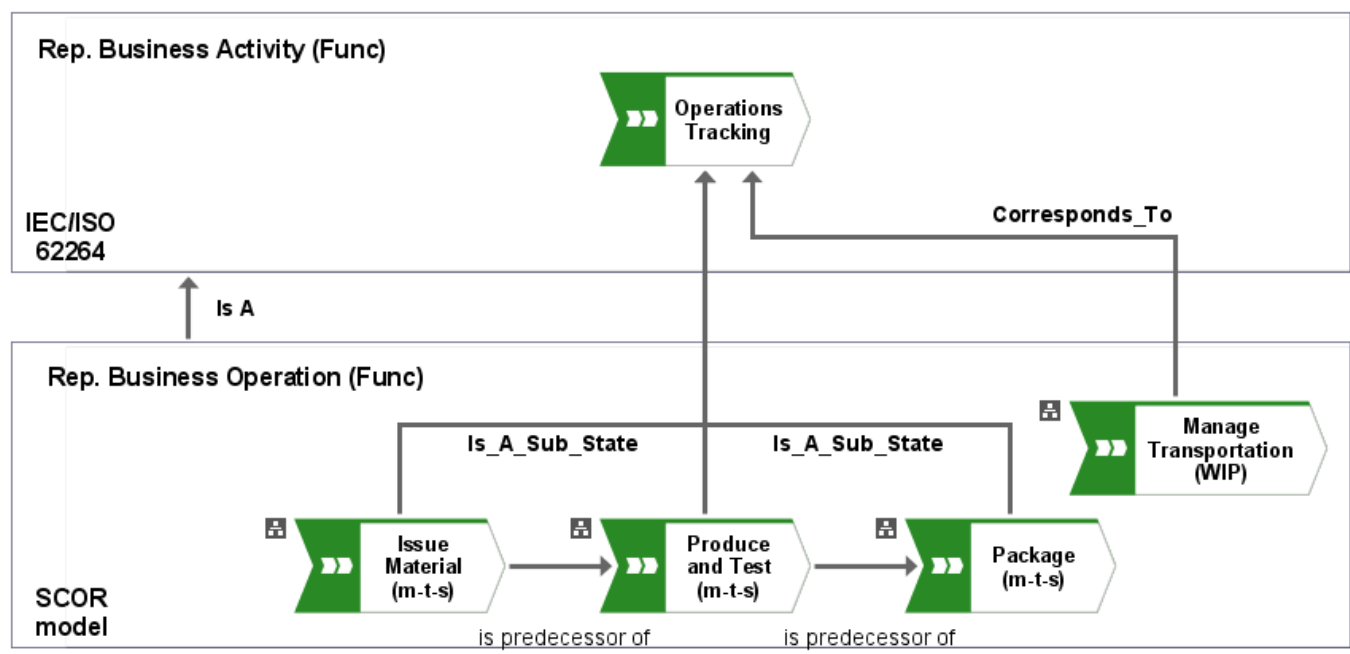

Name: Alignment activity-operation

Type: Value-added chain diagram

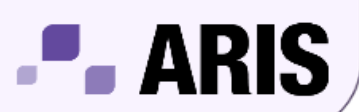

Possible place for Figure 3. Alignment SCOR operations and IEC/IOS62264 activities

The consistency of the alignment has to be checked. The validation is mainly done by multiple business experts, including experts on the IEC/ISO 62264 and on the SCOR model. To facilitate their decision-making, we have developed semantic control rules to check and detect semantic inconsistencies of new additional elements. An example is shown in Figure 4:

- We have one element of information A and two activities B and C from the IEC/ISO 62264, such that ' $A$ is the input of $B$, not of $C$ '.

- Information A1 and function C1 are two variants of the SCOR model, respectively of information $A$ and activity $C$, such that ' $A 1$ is the entry of $C 1$ '.

- Considering that the variants have to inherit the relationship, the semantic check detects an inconsistency, even if the relationship between $\mathrm{A} 1$ and $\mathrm{C} 1$ is well defined in SCOR. The role of the business expert is to make a decision about this relationship.

- The alignment of the two entities $\mathrm{A} 1$ and $\mathrm{C} 1$ of the SCOR model, respectively $\mathrm{A}$ and $\mathrm{C}$, is false. In this case, it is necessary to align them with other entities of the IEC/ISO 62264. If necessary, they must be removed. 
- The alignment is correct. It is then necessary to alter the IEC/ISO 62264 model or the MES repository, by enrichment or updates.

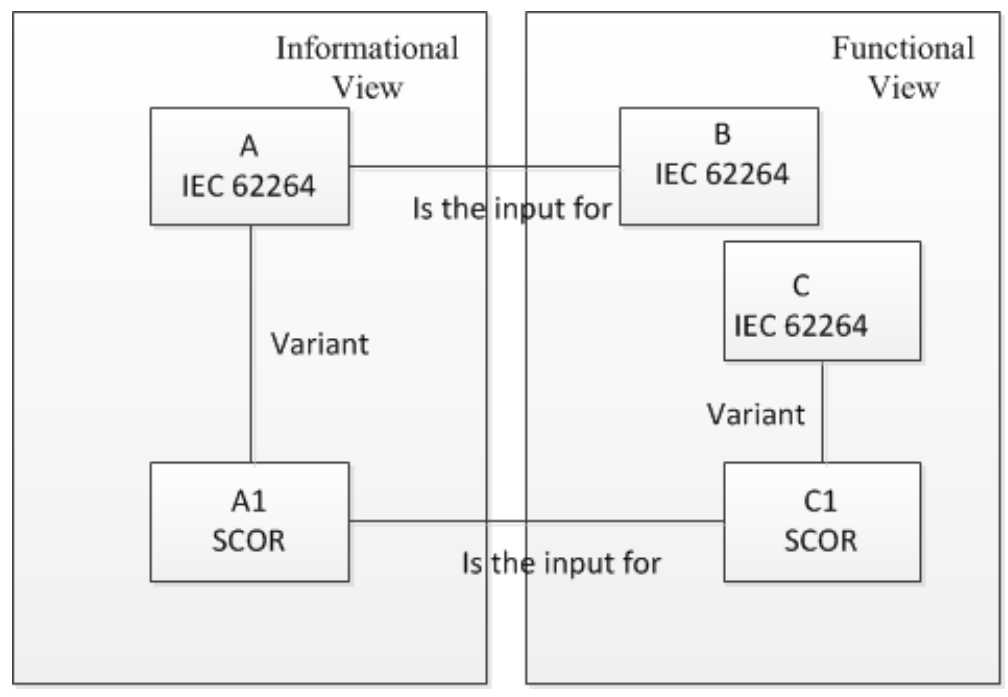

Possible place for Figure 4. Example of semantic inconsistency

A more general definition of this kind of rule is expressed as follows:

- For each piece of information $i_{1}$, input of a function $f_{1}$ of the repository $r_{1}$

- If information $i_{2}$ of repository $r_{2}$ is set as specialization of $i_{1}$ of repository $r_{1}$

- And if function $f_{2}$ of repository $r_{2}$ is set as specialization of $f_{1}$ of repository $r_{1}$

- Then, information $i_{2}$ must be input of function $f_{2}$

\section{Client Requirements Alignment using the repository (Alignment B-C)}

With an enriched business repository, including business expertise on the software applications selected and on known business reference models, the ability to meet client requirements is greater. However, the mapping between this requirement and the business repository is still a challenge. This mapping is made on our modelling platform by creating relations between constructs of repository and projects level.

To define his requirement, a client models a "Client Business Process", using "Client Events" and "Client Business Operations". To be compliant with the IEC/ISO 62264 standard, and to build as many standard processes as possible, that are easier to implement using standard software, the client reuses objects of the standard repository, especially "Repository Business Operations". They can then check the Repository Business Object used in the standard to decide what and how they reuse it in their process. 
Figure 5 shows such a Client Business Process being modelled, using cluster and function as variants of the Repository Business Operation and Repository Business Object. Modelling a client process using standard repository constructs is a very good way to help clients to reuse the MES repository (B-C alignment). To do so, all expertise that can serve to meet the client requirements has to have been implemented in this repository previously (B-B and B-C alignment). A modelling platform focused on repositories, including tools to compare, specialize and evaluate the $\mathrm{B}-\mathrm{C}$ alignment, is required.
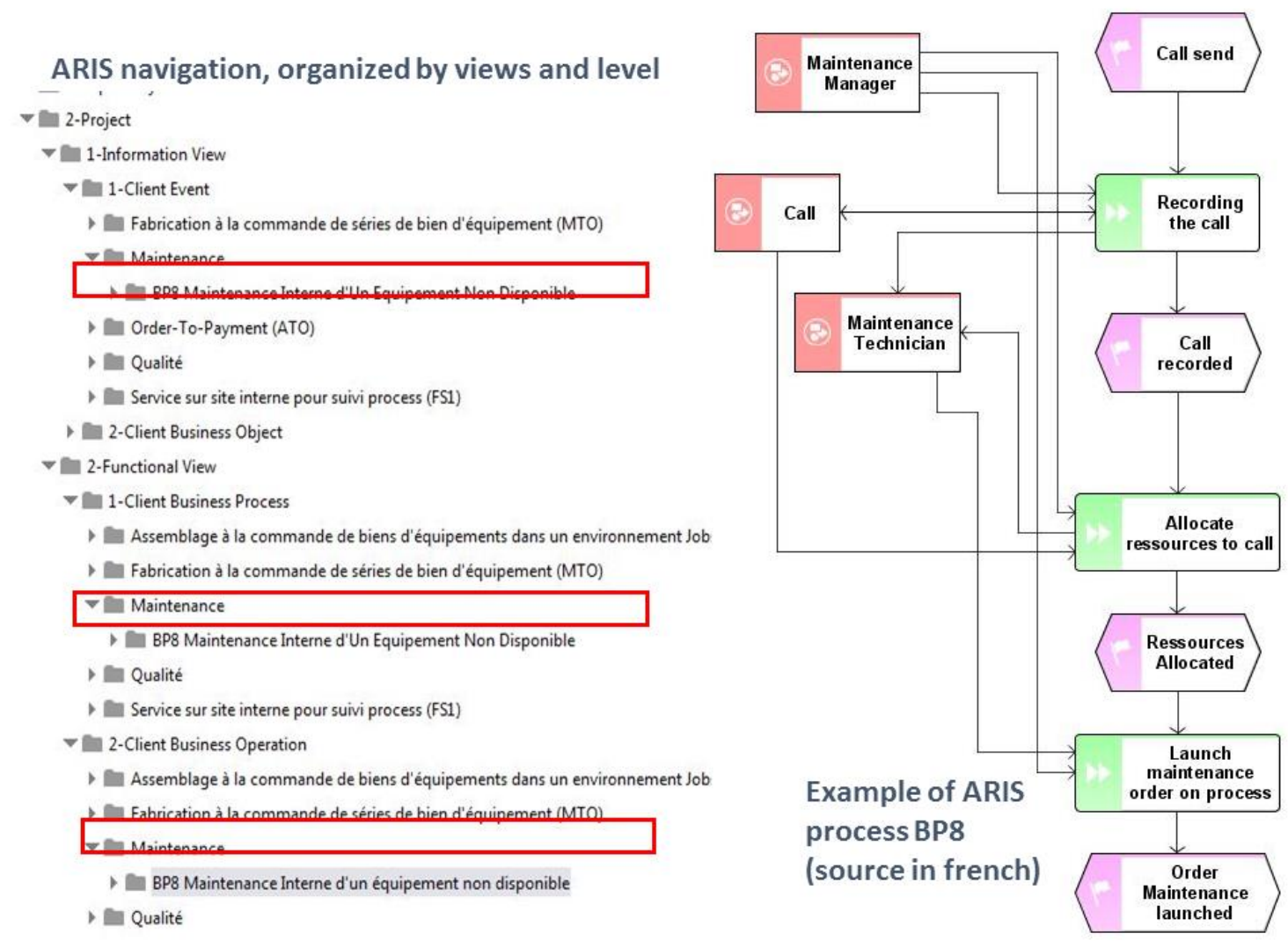

Possible place for Figure 5. Example of a Client Business Process

\section{Evaluation of the proposed repository by MESTRIA Platform}

The repository was built on the ARIS research platform and then transferred to the industrial platform used by software editors (MESTRIA). This allowed us to reuse the repository in other industrial contexts.

The Business Repository is built to be used by clients to ensure that their business objects and processes are "standard compliant". This is not, or not only, for an external compliance constraint, but also to reduce the cost of implementation of these client business objects and processes in the Web services proposed by the software applications. This "B-S" alignment requires the repository business constructs to be linked to the repository functional constructs representing the software packages' capabilities. 
This has to be done by integrating the standard-based reference model into the MESTRIA platform (AGILIUM 2011).This platform offers orchestration of MES services, based on the partners' existing applications (Verjus 2011). It is a Service Oriented Architecture framework, with which services and objects can be defined in XML. To implement our repository on this platform, we built a B2MML extension, including the enrichment of the standard with the constructs from the SCOR reference model and the editor's knowledge.

Figure 6 presents the technical SOA architecture, including the standard B2MML data definition, and its extension required for the MES repository, used by the MESTRIA platform to provide data to Web services. The MES Repository functions are translated into the Web Service Definition (WSDL) XSD extension.

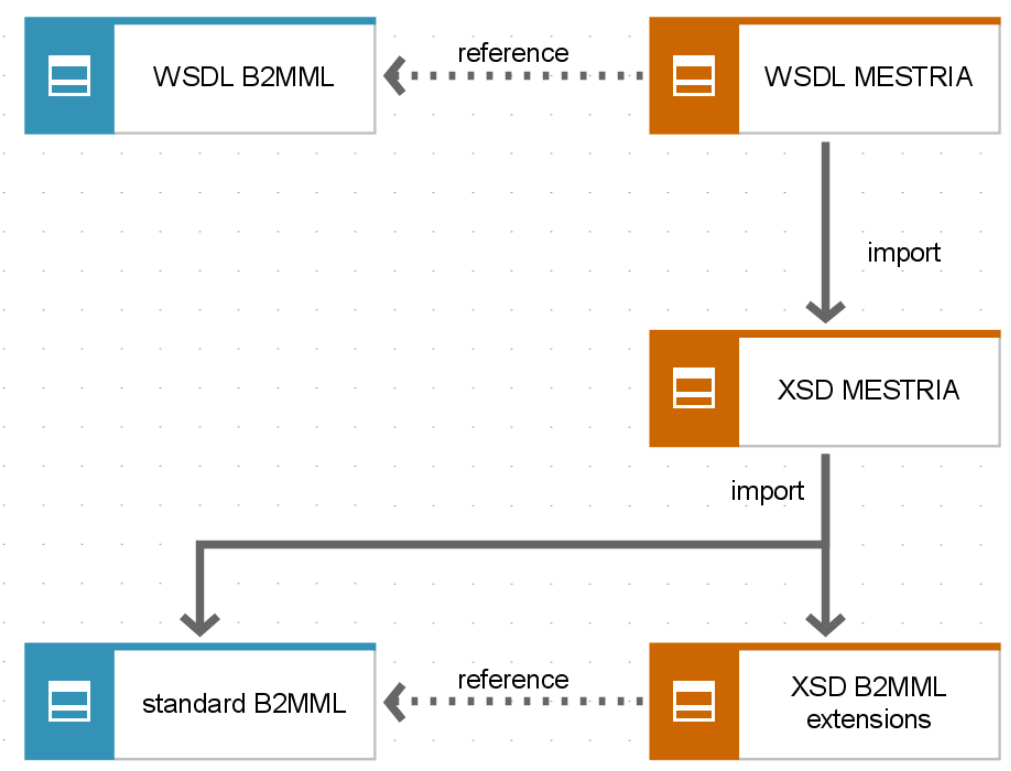

Possible place for Figure 6. MES Repository functions translated into Web service definition (WSDL) XSD extension.

Some examples are in Appendix, including a B2MML extension (WBF 2012) for an equipment type $(A)$, a service operation (B) and an example of a WSDL ${ }^{1}$ service using elements of our extension (C).

MESTRIA is an SOA product dedicated to MES. The modelling of a company scenario is done using the business repository level. The MESTRIA designer help actors of an industrial company to model their specific process using our standard repository. The designer display the $\$ 95$ compliant enriched re-

\footnotetext{
${ }^{1}$ Web Service Definition Language
} 
pository. To express its needs, it can compare its processes with the MES standard repository processes. It then selects standard business objects and processes, if possible, along with customization if so required, to take advantage of the fact that they are already aligned with a software solution.

Its transformation into a technical platform is facilitated using the existing mapping at the repository level between business and functional objects (mainly objects and data for the informational view, and business operations to web service operations for the functional view). The company requirements are modelled on the MESTRIA platform in BPMN language.

The evaluation of our repository was conducted using different real-life oriented business cases proposed by software editors involved in MESTRIA. Each of these cases was modelled using standard business objects and functions from the repository, irrespective of their source, from SCOR, S95, or software editors. The cases were described in terms of the main processes, with some sub-processes, using only constructs of the repository. Their variety illustrates the heterogeneity of the software applications used on the platform: 5 cases regarding production (to order, job-shop, planned, grouping, flow-shop), 3 regarding maintenance (unavailable equipment, predictive, incident), 3 regarding logistics (tools, warehouse inbound, warehouse outbound), and 2 regarding quality (purchase, production). See Annex D.

This demonstrates the capacity of the MES repository to allow modelling of actual business cases from a user perspective, using heterogeneous repositories. Figure 7 presents a global business case of an automotive construction process, including on order production of a car with options (color of the body and of the frame). The process is simulated using a LEGO MindStorm Illustrating Scenario (Verjus 2012), including touch terminals connected to the MES platform This virtual factory allows the piloting and supervising of the different stages of assembly of the car. The integration of a new application for some business functions is easily realized "on-demand" even with some process changes.

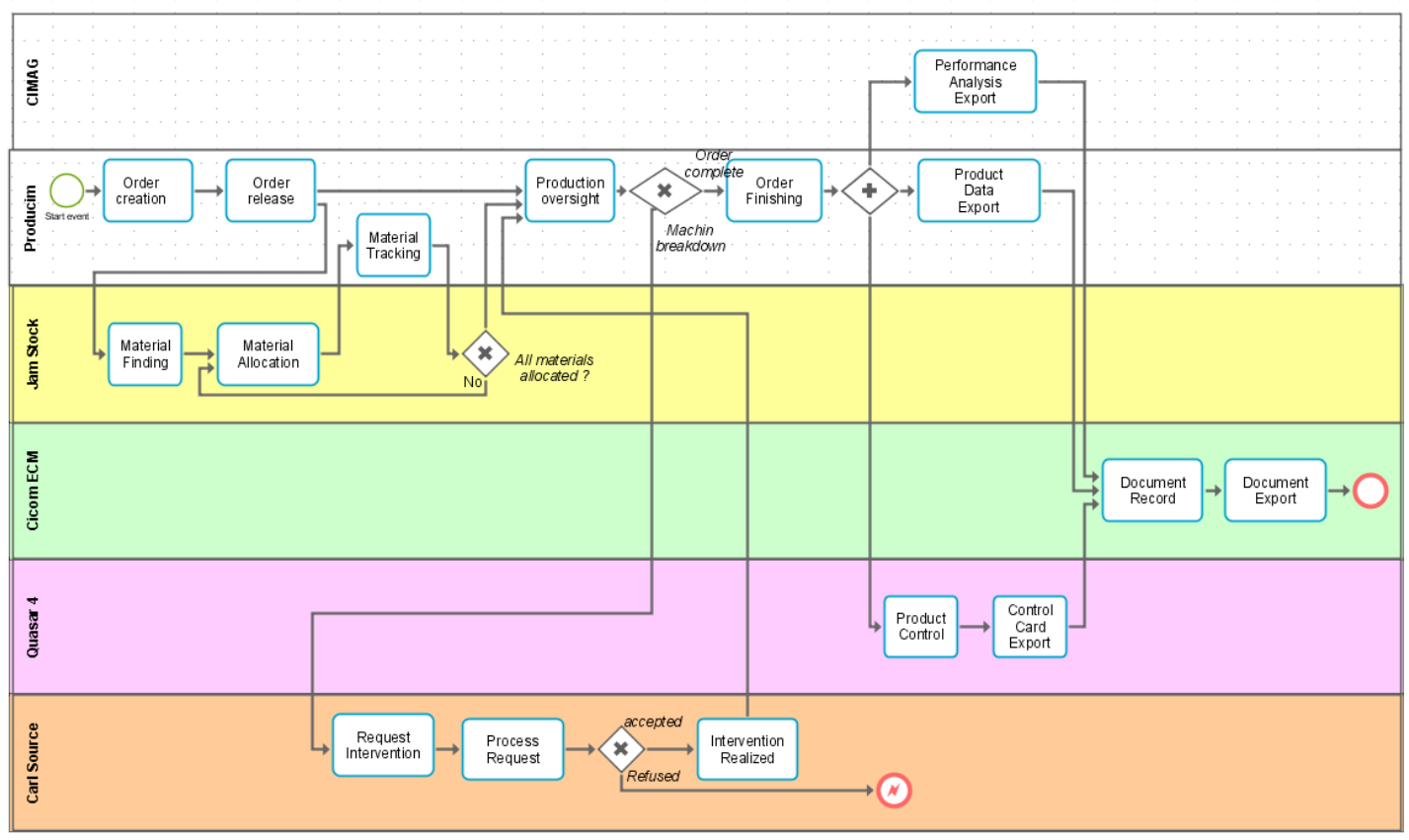

Possible place for Figure 7. The LEGO mindstorm scenario

The MESTRIA platform is then a proof of concept of our scientific contribution, responding to the three alignment issues identified in the Introduction (Figure 1). It validates the capability of the 
framework and the enrichment of ISO/IEC 62264 with others business repositories.

\section{Conclusions}

In this paper we propose to manage the heterogeneity of an "on demand" MES, using an enriched repository compliant with the IEC/ISO 62264 standard, including some concepts of the SCOR reference model, and some capabilities of software packages used by industry. The main contribution is to help MES project actors to master the intrinsic heterogeneity of knowledge involved in MES projects, taking in account three sources of heterogeneous knowledge; customer requirements, business standards, and software capabilities. This lead to take in account three kinds of alignment: between heterogeneous business repositories (B-B), between a business repository and business services of MES software packages (B-S), and finally, between the business repository and the clients' requirements (B-C). We validate our contribution by integrating the MES repository into the MESTRIA platform developed by the consortium, which offers an innovative MES approach allowing clients to build their own "on demand" MES.

The originality is both in the alignment of SCE (SCOR) and MES (IEC/ISO 62264), and in the modeldriven approach to help the experts to solve problems of heterogeneity when building project models.

This allows industries to shorten projects, using the proposed repository to express their requirements, and to ensure a reliable implementation using standard components.

For software editors, the on-demand approach is a key success factor to be selected in manufacturing projects for the core value of their solution.

For researchers, this expert-oriented approach is a pragmatic perspective to address semantic interoperability.

Future extensions of this repository are studied for the OAGIS standard, which defines business objects of ERP systems. The main research perspective is the development of consistency rules for an even more reliable alignment process. The vision is an integrated platform for business experts as a "semantic business model editor", ensuring consistency when accelerating specification and implementation.

\section{Acknowledgment}

We thank the Rhône-Alpes Regional Council (France) and the ERDF (European Regional Development Fund) for their financial support for the "MES project", as part of the EDIT cluster". We also thank all "MES project" members and software editors for their business expertise, and the LISTIC laboratory, which worked on the functional layer and the web services orchestration.

2 The EDIT Cluster was integrated in 2014 into a regional structure named "Clust'R numérique", which merged in 2017 with all regional numeric clusters to become the "digital league" (http://www.digital-league.org/)" 


\section{Language Certificate}

A translator registered in France and specialized in the proof-reading/language editing of academic texts written in English has delivered a certificate and considers that 'as far as the language use is concerned, this paper is now of a publishable standard in leading English-language academic journals'.

\section{References}

Adler, D. J., J. Herkamp,D. Henricks D, and R. Moss. 1995. "Does a manufacturing execution system reduce the cost of production for bulk pharmaceuticals? " ISA Trans 34(4):343-347.

AGILIUM, ‘Le trophée du LABEL MESTRIA', "Salon Progiciels 2011. " Available from: http://www.agilium.com/spip.php?page=article\&id_article=184\&connect=awensys. Accessed 22 February 2016.

Almada-Lobo F. 2015. The Industry 4.0 revolution and the future of Manufacturing Execution Systems (MES), , Journal of Innovation Management, Vol 3, No 4, p 16-21.

Bigand, M., O. Korbaa, and J.P. Bourey. 2004. "Integration of FMS Performance Evaluation Models using Patterns for an Information System Design. " Computers \& Industrial Engineering (46):625-637.

Bussler, C. 2003. B2B Integration, Concepts and Architecture, Springer, June 2003

Chen, D., and G. Doumeingts. 2003. "European Initiatives to Develop Interoperability of Enterprise Applications-Basic Concepts, Framework and Roadmap." Annual Reviews in Control (27):153-162.

Chen, D. , Doumeingts, G. and Vernadat, F. (2008), “Architectures for enterprise integration and interoperability: past, present and future", Computers in Industry, Enterprise Integration and Interoperability in Manufacturing Systems, Vol. 59 No. 7, pp. 647-659. doi: 10.1016/j.compind.2007.12.016.

Guangke, H., H. Weiping, H. Yanli, and Y. Hui. 2009. 'Research on reconfigurability of service-oriented Manufacturing Execution System, " Paper presented at the IEEE 10th International Conference on Computer-Aided Industrial Design \& Conceptual Design. Wenzhou. 26-29 November. doi:

\subsection{9/CAIDCD.2009.5375364}

Hakanson, B. 1996. "MES stands for manufacturing improvements. " IIE Solutions 28(2):27-28

IEC/ISO 62264. 2003. Enterprise-Control System Integration, part 1. AFNOR, PR NF EN 62264-1.

Arab-Mansour I., Millet P.-A., Botta-Genoulaz V. (2017), A business repository enrichment process: A case study for manufacturing execution systems, Computers in Industry, Vol 89, Pages 13-22

ISO/TC and CEN/TC ISO 19439. 2006. Enterprise integration - Framework for Enterprise Modelling, AFNOR. Jung K., S.Choi, B. Kulvatunyou, H. Cho \& K. C. Morris (2017) A reference activity model for smart factory, design and improvement, Production, Planning \& Control, 28:2, 108-122, DOI:10.1080/09537287.2016.1237686 
Klein, M. 2001. $\square$ Combining and Relating Ontologies: an Analysis of Problems and Solutions. $\square$ Paper presented at the Workshop on Ontologies and Information Sharing (47):53-62.

Ding Y., D Fensel, M Klein, B Omelayenko - Data \& Knowledge Engineering, 2002, (41, n 2): $205-227$

Koslowski, T., J. Strüker, ERP On Demand Platform, Business \& Information System Engineering (2011) vol 3 (6), pp 359-367, doi:10.1007/s12599-011-0187-z

Larson, M. 1997. "Gain shop-floor control with MES software. " Quality 36(6):68-70.

Levrat E., B. Iung \& A. Crespo Marquez (2008), E-maintenance: review and conceptual framework, Production Planning \& Control, 19:4, 408-429, DOI: 10.1080/09537280802062571

Marks, E. A., and M. Bell. 2006. Service Oriented Architecture (SOA): A Planning and Implementation Guide for Business and Technology. New Jersey: John Wiley \& Sons.

MESA, 1997a. White Paper \#02: MES Functionalities and MRP to MES Data Flow Possibilities [online]. MESA International. Available from: https://services.mesa.org/resourcelibrary/showresource/2cedfe75-daed-4b9c-b187f421cf90fdd2. Accessed 22 January 2016.

MESA, 1997b. White Paper \#06: MES Explained: A High Level Vision for Executives [online]. MESA International. Available from: https://services.mesa.org/resourcelibrary/showresource/334444c5-388f-4360-beb43c86dc0f4de4. Accessed 22 January 2016.

Panetto, H., and A. Molina A. 2008. ”Enterprise Integration and Interoperability in Manufacturing Systems: Trends and Issues." Computers in Industry (59): 641-646.

Ram S., J. Park, 2004 "Semantic conflict resolution ontology (scrol): An ontology for detecting and resolving data and schema level conflicts", IEEE Transactions on Knowledge and Data Engineering, vol. 16, no. 2, pp. 189-202.

Sakka, O., P.-A. Millet, V. Botta-Genoulaz. 2011. “An ontological approach for strategic alignment: a SCOR case study" International Journal of Computer Integrated Manufacturing, Special Issue: Enterprise Engineering and Alignment (24, Issue 11): 1022-1037

Saenz de Ugarte, B., A. Artiba, and R. Pellerin. 2009. "Manufacturing execution system - a literature review.

“ Production Planning \& Control 20:6, 525-539, DOI: 10.1080/09537280902938613.

SCC: Supply-Chain Council. SCOR Supply Chain Operations Reference Model version 9.0 (2009), http://www.supplychainworld.org/na/. 
Ulmer, J.-S. “A pivotal-based approach for enterprise business process and IS integration”. Enterprise Information Systems (EIS), 2013, vol7, Issue 1, pp. 61-78.

Scheer, A. W., K. Schneider. 2005. Handbook on Architectures of Information Systems. Berlin: Springer. Teran H., Hernandez J.-C., Vizán A. \& Ríos J. (2014), Performance measurement integrated information framework in e-Manufacturing, Enterprise Information Systems, 8:6, 607-629, DOI: 10.1080/17517575.2012.754950 Verjus, H. 2011. "MESTRIA: le pilotage d'Atelier à la Carte. " Available from: http://www.jiteconline.com/mestria_le_pilotage_d_atelier_a_la_carte-fr1827.html. Accessed 22 February 2016.

Verjus, H. 2012. "An SOA-based Manufacturing Executing System (MES) - Application to a LEGO MindStorm Illustrating Scenario. " Available from: http://www.herveverjus.com/index.php?post/2012/03/15/An-SOA-basedPlatform-For-a-Manufacturing-Executing-System-\%28MES\%29-A-LEGO-MindStorm-Illustrating-Scenario. Accessed 22 February 2016.

Verjus H., F. Pourraz, N. Fakhfakh (2011), Cadre conceptuel pour la modélisation et la supervision d'architectures à base de services. Une approche pour l'ingénierie des SI à base de services. Revue des Sciences et Technologies de l'Information - Série ISI : Ingénierie des Systèmes d'Information, Lavoisier, 2011, 16 (5), pp.43-72. Vernadat, J.F.. 2010. "Technical, semantic and organizational issues of enterprise interoperability and networking." Annual Reviews in Control (34-1): 139-144.

Vinhais, J. A. 1998. "Manufacturing execution systems: the one-stop information source. " Quality Digest 18(9):39-40. Available at http://www.qualitydigest.com/sept98/html/mes.html. Accessed 22 February 2016. Vinhais, J. A. 2004. "MES reduces FDA compliance costs. " Quality 43(2):38-41.

WBF 2012: B2MML schema. B2MML-BatchML-V0401-Schema.zip Available from: https://services.mesa.org/resourcelibrary/showresource/85b4d2b3-5eba-44f0-a2c4-f535169f961b. Accessed 04 April 2017. Yahia, E., A. Aubry, and H. Panetto. 2012. "Formal Measures for Semantic Interoperability Assessment in Cooperative Enterprise Information Systems." Computers in Industry (63):443-457.

Zdravkovic, M. 2012. "Formal framework for semantic interoperability in supply chain networks". Thesis, Faculty of Mechanical Engineering in Niš. 


\section{Appendices}

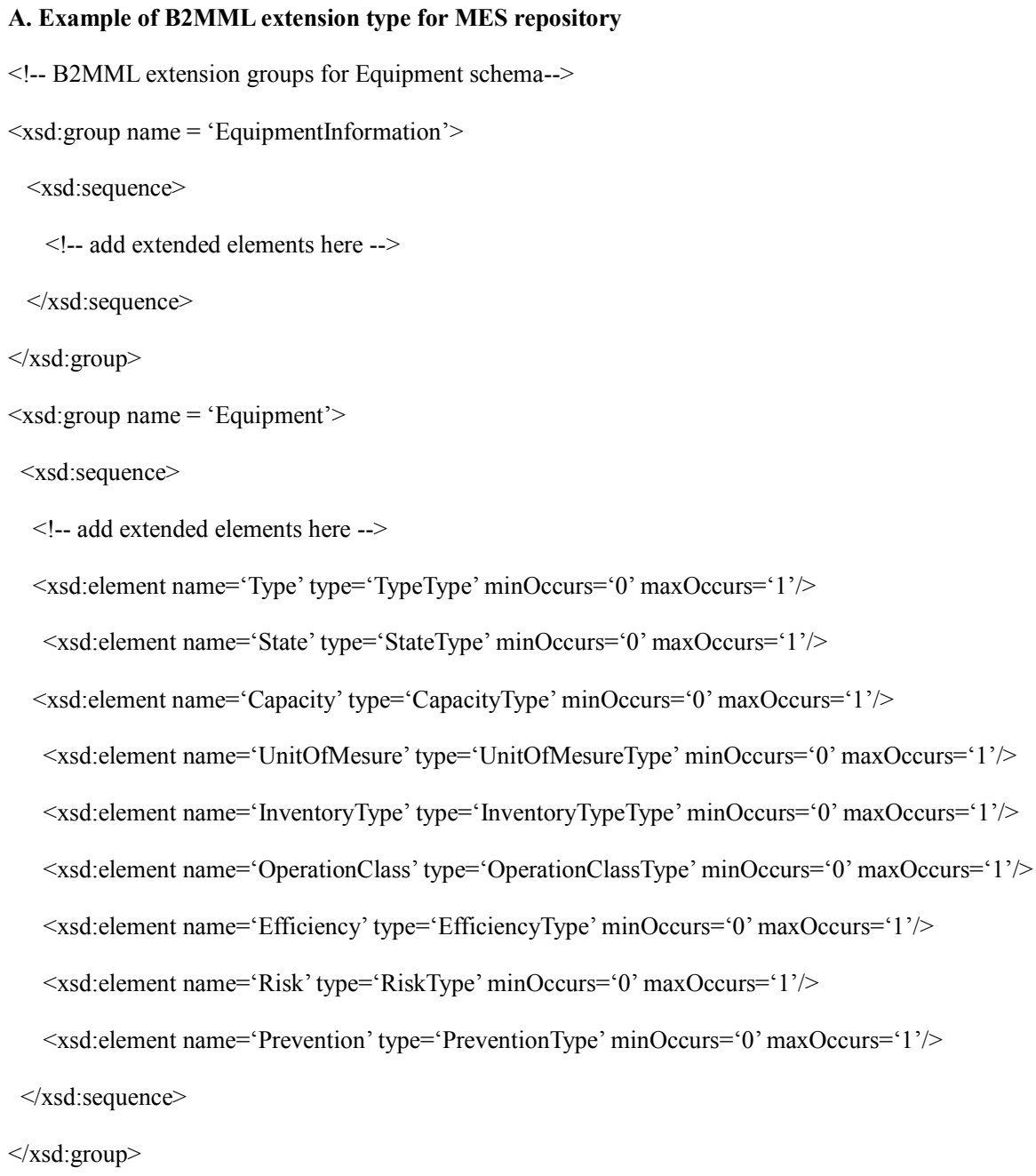

\section{B. Example of a service operation}

$<$ OperationsSchedule $>$

$<$ PublishedDate $>$ Date de Création $<$ /PublishedDate $>$

$<$ OperationsRequest $>$

$<$ Description $>$ Libellé $</$ Description $>$

$<$ Description $>$ Commentaire $<$ /Description $>$

$<$ HierarchyScope $>$

$<$ EquipmentID $>$ Centre de coût $</$ EquipmentID $>$

$<$ EquipmentElementLevel $>$ 'Work Center' $<$ /EquipmentElementLevel $>$

$<$ HierarchyScope $>$

$<$ EquipmentID $>$ Location $<$ EquipmentID $>$

$<$ EquipmentElementLevel $>$ 'Work Unit' $<$ /EquipmentElementLevel $>$

$</$ HierarchyScope $>$ 


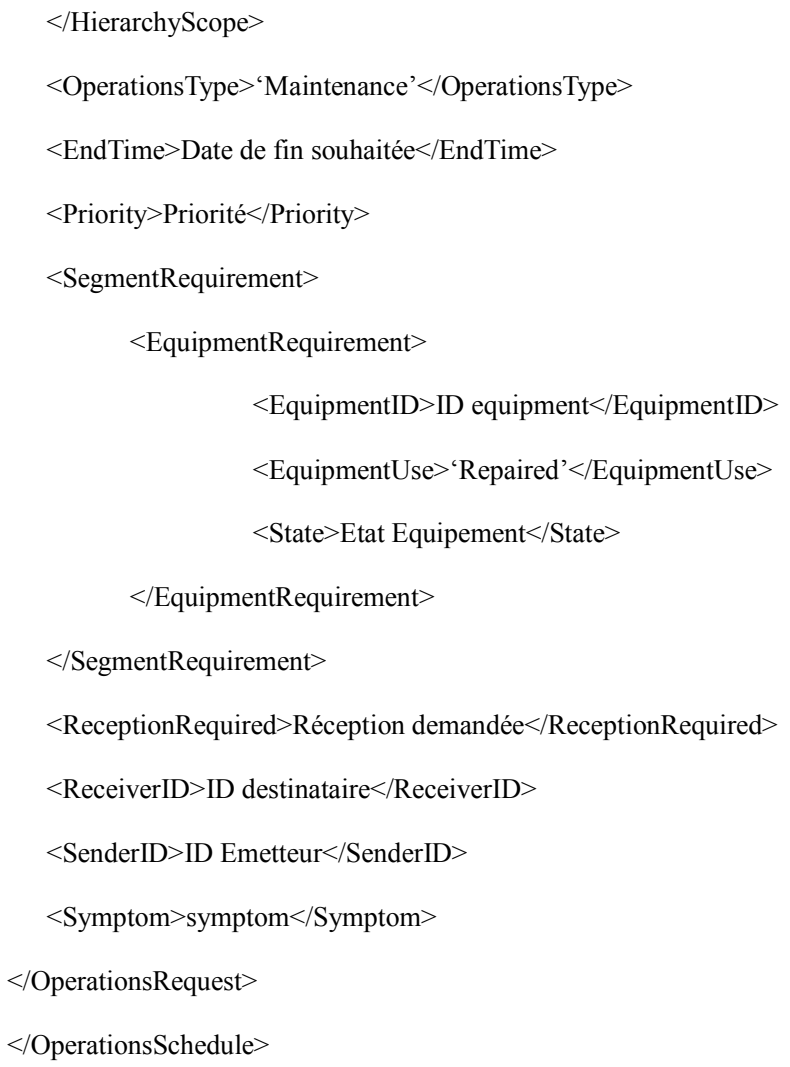

\section{Example of a WSDL service definition using B2MML in the MES platform}

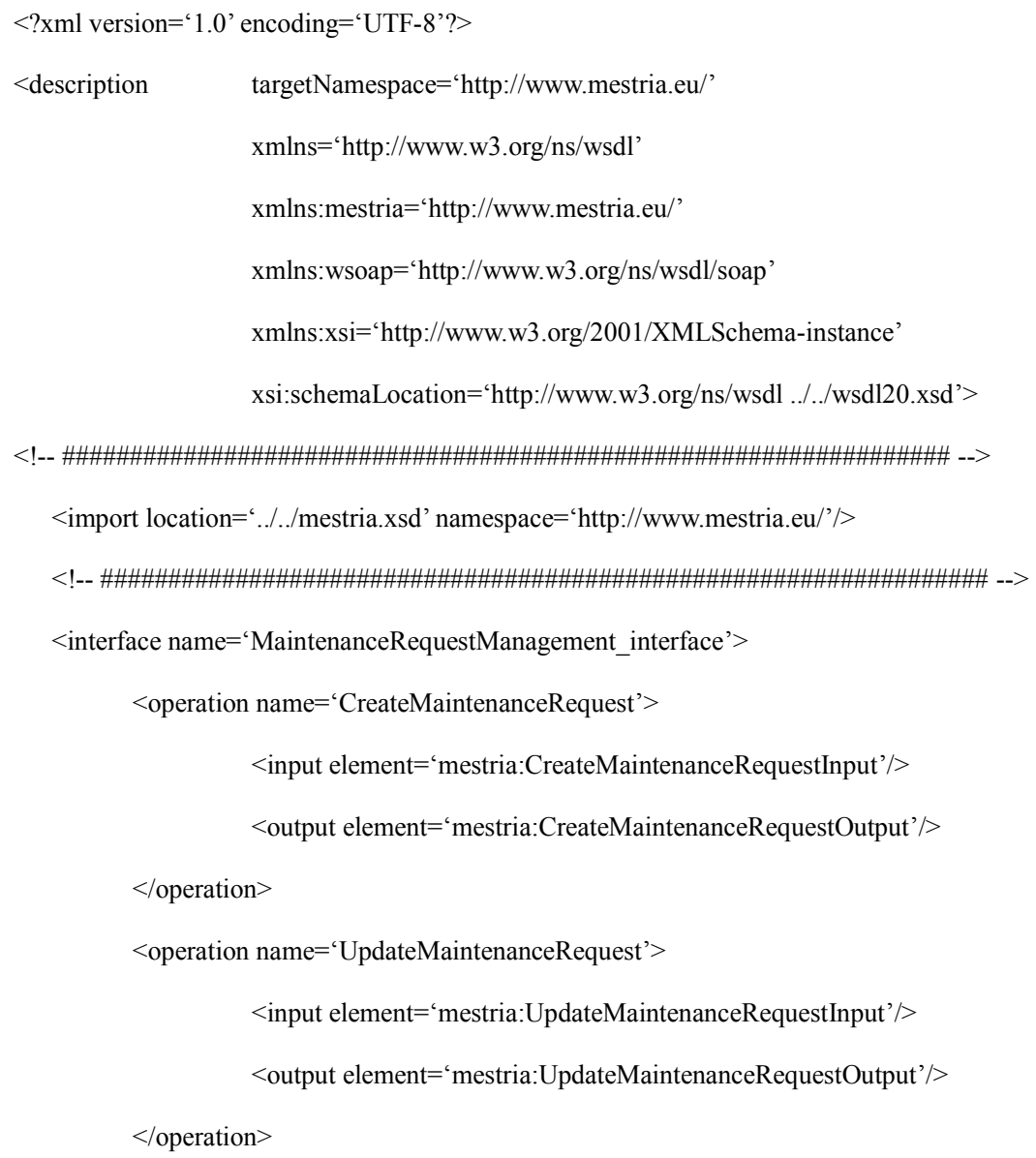




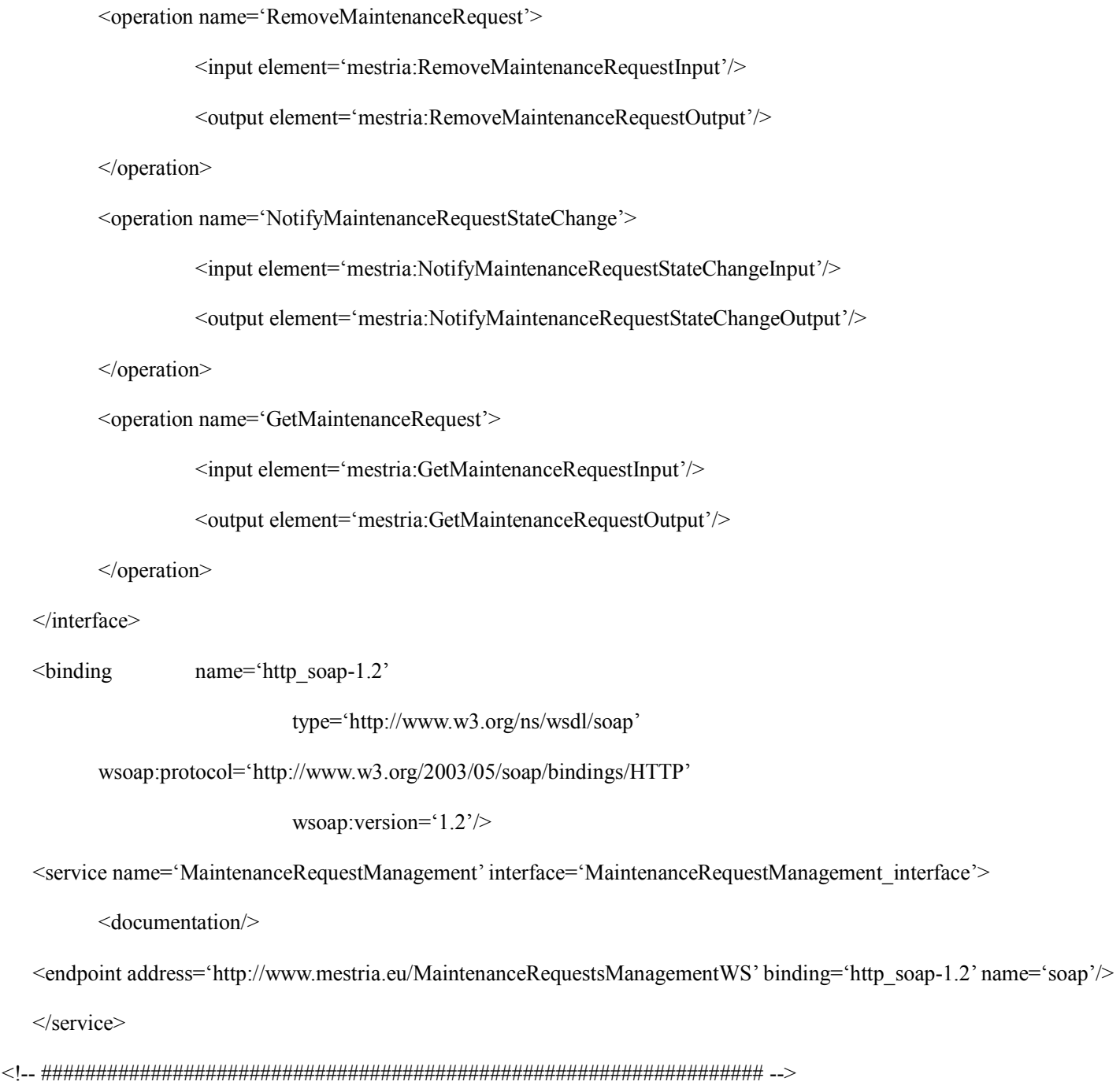

\section{List of business cases used for platform validation}

- $\quad$ Production triggered to produce according to the client order

- Production triggered to produce according to a plan

- $\quad$ Production of a manufacturing order (jobshop)

- Material outbound for a manufacturing order (jobshop) using a storage machine

- Tools outbound for manufacturing order

- Warehouse inbound after production delivering

- Warehouse outbound for manufacturing order

- Scheduling of group of order on production line

- Production of group of order on production line

- Maintenance order on machine following incident

- Quality control in warehouse inbound (purchase)

- Quality control for production 
- Internal maintenance for unavailable equipment

- Production data collect for predictive maintenance

Tables and Figures

Table 1. The ARIS objects used

Table 2. MES repository contents after enrichment by elements of the functional layer

Figure 1. Three issues of alignment involving the business layer

Figure 2. Alignment MES meta-model.

Figure 3. Alignment SCOR operations and IEC/IOS62264 activities

Figure 4. Example of semantic inconsistency

Figure 5. Example of client business process

Figure 6. MES Repository functions translated into Web service definition (WSDL) XSD extension

Figure 7. Example of a client process being created using MES proposed repository

Figure 8. The LEGO mindstorm scenario 